\title{
Rhamnolipids Increase the Phytotoxicity of Diesel Oil Towards Four Common Plant Species in a Terrestrial Environment
}

\author{
Roman Marecik • Joanna Wojtera-Kwiczor • \\ Lukasz Lawniczak • Pawel Cyplik • Alicja Szulc • \\ Agnieszka Piotrowska-Cyplik • \\ Lukasz Chrzanowski
}

Received: 5 January 2012 / Accepted: 23 April 2012 /Published online: 17 May 2012

(C) The Author(s) 2012. This article is published with open access at Springerlink.com

\begin{abstract}
The study focused on assessing the influence of rhamnolipids on the phytotoxicity of diesel oil-contaminated soil samples. Tests evaluating the seed germination and growth inhibition of four terrestrial plant species (alfalfa, sorghum, mustard and cuckooflower) were carried out at different rhamnolipid concentrations (ranging from 0 to $1.200 \mathrm{mg} / \mathrm{kg}$ of wet soil). The experiments were performed in soil
\end{abstract}

\footnotetext{
R. Marecik $\cdot$ P. Cyplik

Department of Biotechnology and Food Microbiology,

University of Life Sciences in Poznań,

Wojska Polskiego 48,

60-627 Poznań, Poland

J. Wojtera-Kwiczor

Department of Biochemistry, Institute of Molecular Biology and Biotechnology, Adam Mickiewicz University in

Poznan,

Umultowska 89,

61-614 Poznań, Poland

Ł. Ławniczak $\cdot$ A. Szulc $\cdot$ Ł. Chrzanowski $(\bowtie)$

Institute of Chemical Technology and Engineering, Poznań

University of Technology,

P1. M. Skłodowskiej-Curie 2,

60-965 Poznań, Poland

e-mail: lucaschrz@gmx.de
}

\author{
A. Piotrowska-Cyplik \\ Institute of Food Technology of Plant Origin, \\ University of Life Sciences in Poznań, \\ Wojska Polskiego 31, \\ 60-624 Poznań, Poland
}

samples with a different diesel oil content (ranging from 0 to $25 \mathrm{ml} / \mathrm{kg}$ of wet soil). It was observed that the sole presence of rhamnolipids may be phytotoxic at various levels, which is especially notable for sorghum (the germination index decreased to $41 \%$ ). The addition of rhamnolipids to diesel oil-contaminated soil samples contributed to a significant increase of their phytotoxicity. The most toxic effect was observed after a rhamnolipid-supplemented diesel oil biodegradation, carried out with the use of a hydrocarbondegrading bacteria consortium. The supplemention of rhamnolipids $(600 \mathrm{mg} / \mathrm{kg}$ of wet soil) resulted in a decrease of seed germination of all studied plant species and an inhibition of microbial activity, which was measured by the 2,3,5-triphenyltetrazolium chloride tests. These findings indicate that the presence of rhamnolipids may considerably increase the phytotoxicity of diesel oil. Therefore, their use at high concentrations, during in situ bioremediation processes, should be avoided in a terrestrial environment.

Keywords Bacterial consortium · Diesel oil · Rhamnolipids · Seed germination · Phytotoxicity

\section{Introduction}

The use of biosurfactants has been recognised as an environmentally friendly way of enhancing the removal 
of petroleum products from contaminated soil (Mulligan 2009). However, several studies, concerning the phytoextraction of heavy metals, indicate that rhamnolipids, a well-described group of biosurfactants, may contribute to an inhibition of plant growth (Wen et al. 2010; Gunawardana et al. 2010). A toxic effect of rhamnolipids was observed at the concentration of $2.5 \mathrm{~g}$ per $1 \mathrm{~kg}$ soil (Wen et al. 2010). Although the application of rhamnolipids contributes to an increased effectiveness of soil flushing processes (at concentrations up to $50 \mathrm{~g}$ per $1 \mathrm{~kg}$ soil), as well as a higher biodegradation efficiency (at average concentrations below $1 \mathrm{~g} / \mathrm{l}$ ) (Urum et al. 2004; Santa Anna et al. 2007; Makkar and Rockne 2003), the number of studies focused on assessing their effect on phytotoxicity in a petroleum-contaminated terrestrial environment is very limited (Millioli et al. 2009). With this in mind, we investigated the influence of rhamnolipids on the seed germination and growth of four common terrestrial plant species (alfalfa, sorghum, mustard and cuckooflower) in diesel oil-contaminated soil samples. A wide range of concentrations was investigated for both rhamnolipids and diesel oil. Additionally, phytotoxic effects were investigated during a biodegradation of diesel oil, carried out by a bacterial consortium consisting of hydrocarbon degraders, with and without the addition of rhamnolipids. The results of this study may provide an interesting insight into the potential toxicity of rhamnolipids, applied during the bioremediation of petroleum-contaminated soil.

\section{Materials and Methods}

\subsection{Chemical Reagents}

Petroleum diesel oil (EN 590:2004) was purchased from PKN Orlen, Poland. Rhamnolipids, in a form of a commercially available product JBR-425 (25\% aqueous solution), were obtained from the Jeneil Biosurfactant Company (Saukville, WI, USA). The mixture contains mainly rhamnolipid RL1 (rhamnosyl- $\beta$-hydroxydeca noyl- $\beta$-hydroxydecanoate) and RL2 (L-rhamnosyl-Lrhamnosyl- $\beta$-hydroxydecanoyl- $\beta$-hydroxydecanoate). The concentrations of rhamnolipids used during the studies were selected based on their critical micelle concentration (CMC) value (approximately $150 \mathrm{mg} / \mathrm{l}$ ).

\subsection{Microorganisms}

The microbial consortium used throughout this study was isolated from a crude oil-contaminated site in Czarna, Poland and exhibited an excellent biodegrading potential towards diesel oil (Owsianiak, Chrzanowski et al. 2009). The diesel-degrading consortium was previously identified and described as belonging to the following bacteria and archaea: Pseudomonas alcaligenes, Ochrobactrum intermedium, Sphingobacterium sp., Pseudomonas putida, Klebsiella oxytoca, Chryseobacterium sp. and Stenotrophomonas maltophilia (Owsianiak, Szulc et al. 2009). The consortium did not exhibit the ability to exert any indigenous biosurfactants during this study.

\subsection{Plants}

The plants used throughout this study belonged to the following species: alfalfa (Medicago sativa), sorghum (Sorghum saccharatum), mustard (Sinapis alba) and cuckooflower (Cardamine pratensis). These plant species are commonly used for phytotoxicity tests. The plant seeds were purchased commercially.

\subsection{Seed Germination}

The phytotoxicity of rhamnolipids, applied in the range of $75-1.200 \mathrm{mg} / \mathrm{kg}$ of wet soil, was studied during biodegradation of petroleum hydrocarbons (Makkar and Rockne 2003). Control soil (OECD (Organisation for Economic Cooperation and Development) 1984), used in the germination test (gravimetric water content at $18 \%$ ), was acquired commercially (Phytotoxkit tests, Tigret, Warsaw). It was supplemented with diesel oil, at a rising concentration of 0 to $25 \mathrm{ml} / \mathrm{kg}$ of wet soil.

The seed germination test was performed in Petri dishes, filled with $50 \mathrm{~g}$ of the control soil, with the following sets of experiments: (1) control (seeds in distilled water); (2) control conditions supplemented with rhamnolipids only (at $0,75,150,300,600$ and $1.200 \mathrm{mg} / \mathrm{kg}$ of wet soil); (3) seeds germinated in a diesel oil-contaminated soil (at 0, 0.5, 1, 2.5, 5, 10 and $25 \mathrm{ml} / \mathrm{kg}$ of wet soil), supplemented with rhamnolipids (at $0,75,150,300,600$ and $1.200 \mathrm{mg} / \mathrm{kg}$ of wet soil); and (4) seeds germinated in a diesel oil-contaminated soil (diesel oil at $0,0.5,1,2.5,5,10$ and $25 \mathrm{ml} / \mathrm{kg}$ of wet soil), supplemented with rhamnolipids (at 0,150 and 
$600 \mathrm{mg} / \mathrm{kg}$ of wet soil) and with the microbial consortium (Owsianiak, Chrzanowski et al. 2009). The control soil was additionally amended with a culture medium, in order to obtain the optimal microbial growth conditions (Owsianiak, Szulc et al. 2009).

After mixing the soil with an appropriate amount of rhamnolipids and diesel oil, a filter paper was transferred onto the soil filled in the Petri dish, and 30 plant seeds were placed on the top of it. Each sample was prepared in three replicates. The dishes were stored in the dark at $25^{\circ} \mathrm{C}$. The percentage of germinated seeds (seeds with at least 5-mm long radicles) and radicle length were assessed after 7 days. The germination index was calculated according to these results (Mosse et al. 2010):

Germination $\operatorname{index}(\mathrm{GI})=\frac{G_{\mathrm{x}}}{G_{\mathrm{c}}} \times \frac{L_{\mathrm{x}}}{L_{\mathrm{c}}} \times 100[\%]$

where $G_{\mathrm{x}}$ and $G_{\mathrm{c}}$ are the number of seeds germinated in the sample and control, respectively, whereas $L_{\mathrm{x}}$ and $L_{\mathrm{c}}$ are the length of the radicle in the sample and control, respectively.

\subsection{Plant Growth}

The plant growth studies were carried out in pots, filled with $500 \mathrm{~g}$ of control soil (Tigret, Warsaw), with ten seedlings planted per pot. One uncontaminated soil sample used as a control and other samples were amended with an appropriate amount of rhamnolipids (150 and $600 \mathrm{mg} / \mathrm{kg}$ of wet soil) and with diesel oil $(0,0.5,1,2.5,5,10$ and $25 \mathrm{ml} / \mathrm{kg}$ of wet soil). Each sample was prepared in three replicates, with a total of 45 pots for each studied plant species. The seedling was grown at an average temperature of $25^{\circ} \mathrm{C}$, an average light intensity of $450 \mu \mathrm{mol} \mathrm{s} \mathrm{m}^{-1}$ and a 16-h photoperiod (Mosse et al. 2010). After 7 days, the plants were destructively harvested and carefully rinsed with redistilled water and the roots and shoots were separated. The tissues were dried for $48 \mathrm{~h}$ at $70^{\circ} \mathrm{C}$, and the dry matter was assessed.

\subsection{Determination of Total Petroleum Hydrocarbon} After the Biodegradation

The total petroleum hydrocarbon (TPH) biodegradation was determined according to the procedure described previously by Owsianiak, Chrzanowski et al. (2009).

\subsection{Microbial Activity in Soil}

The activity of the microbial consortium is reflected by the activity of bacteria dehydrogenases that are able to reduce 2,3,5-triphenyltetrazolium chloride (TTC) to a red product, triphenyl formazan (TPF). The so-called TTC method has been widely used for monitoring the activity of soil microorganisms, and it was recently proposed for screening of the hydrocarbon degraders (Margesin et al. 2000). After the germination test, the soil samples from the Petri dishes $(0.5 \mathrm{~g})$ were vortexed with $25 \mathrm{ml}$ of a freshly added mineral medium. A total of $7.5 \mathrm{ml} \mathrm{TTC}$ solution $(4 \mathrm{mg} / \mathrm{ml}$, in $0.05 \mathrm{M}$ Tris buffer) was added to each sample and then vortexed for $1 \mathrm{~min}$ at 2,500 rpm and incubated for $30 \mathrm{~min}$ at $30^{\circ} \mathrm{C}$. Afterwards, the samples were centrifuged for $15 \mathrm{~min}$ at $3,000 \times \mathrm{g}$, the supernatant was removed and the soil slurry was vortexed for $1 \mathrm{~min}$ with $5 \mathrm{ml}$ of $96 \%$ ethanol and left for $30 \mathrm{~min}$ in the dark, for a complete TPF extraction. Since a part of TPF partitioned into residual diesel components, which leads to significant underestimation errors, $n$-hexane was added as a final extraction step ( $2 \mathrm{ml}, 30 \mathrm{~min})$. Absorbance of TPF was measured at $490 \mathrm{~nm}$ against $n$ hexane serving as a reference. The activity of dehydrogenases is expressed in micromolar.

\section{Results and Discussion}

\subsection{Phytotoxicity}

The initial germination tests were performed without any diesel oil addition, in order to evaluate the toxicity of rhamnolipids towards plants only (Fig. 1). The biosurfactant did not exhibit any phytotoxicity at lower concentrations $(75 \mathrm{mg} / \mathrm{kg})$, although an increase in the concentration of rhamnolipids resulted in a decrease of the GI for alfalfa, mustard and sorghum. The decrease of GI was moderate for alfalfa and mustard and most notable for sorghum (GI dropped to 70,71 , and $41 \%$, respectively). The cuckooflower species remained unaffected.

As demonstrated by Millioli et al. (2009), the sole presence of rhamnolipids may influence the GI of lettuce (Lactuca sativa) (Millioli et al. 2009). The authors report that in the case of the latter species, the GI dropped below $50 \%$ at a rhamnolipid concentration of 


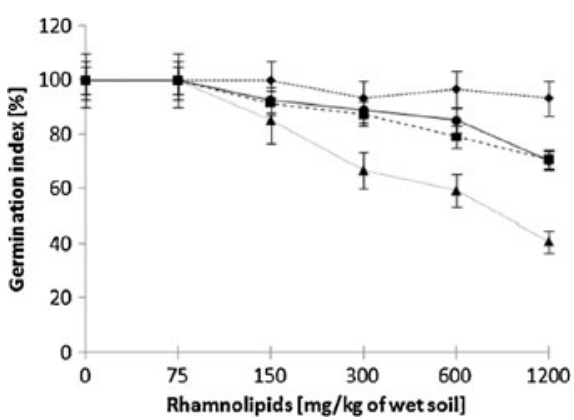

Fig. 1 Influence of rhamnolipids on the germination index of four studied plant species, after 7-day germination. Alfalfa is indicated by circles, mustard by squares, sorghum by triangles and cuckooflower by diamonds

$4 \mathrm{~g} / \mathrm{kg}$, decreasing further to $30 \%$ with an increase of the rhamnolipids content (up to $16 \mathrm{~g} / \mathrm{kg}$ ). Interestingly, the presence of rhamnolipids had a much less negative impact on the germination of three out of four plant species tested in our study, at a range of concentrations between 0.75 and $1.2 \mathrm{~g} / \mathrm{kg}$. However, the experiments performed by Silva et al. (2010) indicate that cabbage (Brassica oleracea) may tolerate the sole presence of rhamnolipids without any significant drop of its GI (Silva et al. 2010). This contributes to a hypothesis that the phytotoxicity of rhamnolipids may be species related.

Further germination experiments were focused on assessing the phytotoxicity of a diesel oil-contaminated soil, which was supplemented with rhamnolipids (Fig. 2). The combination of the named xenobiotics contributed to a drop of the GI in the case of all studied plant species, which was the most significant at the highest concentration of both compounds. The cuckooflower plants were the most tolerant at low concentrations of rhamnolipids (up to $300 \mathrm{mg} / \mathrm{kg}$ ) and at higher content of diesel oil (up to $10 \mathrm{ml} / \mathrm{kg}$ ) (Fig. 2d). In the case of mustard seeds, the GI remained high (66-100\%) at the moderate concentration of diesel oil (up to 2.5 $\mathrm{ml} / \mathrm{kg}$ ) and up to $600 \mathrm{mg} / \mathrm{kg}$ of rhamnolipids (Fig. 2b), whereas in this given range of both compounds, the GI of alfalfa is already in the range between 33 and $66 \%$ (Fig. 2a). Interestingly, in the presence of the highest concentration of diesel oil, mustard seeds seem to be 23 less tolerant than alfalfa, even at small amounts of rhamnolipids in the contaminated soil (Fig. 2b), whereas alfalfa's GI is located in the range below $33 \%$ first at a concentration of approximately
$100 \mathrm{mg} / \mathrm{kg}$ of rhamnolipids (Fig. 2a). Although the cuckooflower plants display the highest tolerance regarding germination rate towards both diesel oil and rhamnolipids, the decrease of the GI below $33 \%$ is higher when compared with alfalfa and mustard plants.

The decrease of the GI was most notable for sorghum (Fig. 2c), in comparison with the other three species, while the alfalfa and mustard plants exhibited the highest tolerance at the high rhamnolipid and diesel oil concentrations (above $300 \mathrm{mg} / \mathrm{kg}$ and $5 \mathrm{ml} / \mathrm{kg}$, respectively). In the samples with a moderate diesel oil contamination (between 1 and $5 \mathrm{ml} / \mathrm{kg}$ ), notable changes in the GI value occurred at two rhamnolipid concentrations: 150 and $600 \mathrm{mg} / \mathrm{kg}$. Interestingly, the $\mathrm{CMC}$ value for a mixture of rhamnolipids is between 50 and $200 \mathrm{mg} / \mathrm{l}$ (Chrzanowski et al. 2009; Pornsunthorntawee et al. 2009; Guo et al. 2009). Since the notable changes in the GI value occurred approximately at two rhamnolipid concentrations 150 and $600 \mathrm{mg} / \mathrm{kg}$, where the first concentration belongs to the $\mathrm{CMC}$ range and the second is far above it, these two concentrations were chosen for further studies.

The results obtained by Millioli et al. (2009) indicate that the presence of rhamnolipids in a crude oilcontaminated soil (TPH at about $60 \mathrm{ml} / \mathrm{kg}$ ) results in an increased toxicity towards lettuce, with a complete inhibition of seed germination at $8 \mathrm{~g} / \mathrm{kg}$ of rhamnolipids (Millioli et al. 2009). As reported by Millioli et al. (2009), it can be concluded that the combination of diesel oil and rhamnolipids may exhibit a notable phytotoxic effect on certain species of plants, even at considerably lower concentrations. This high phytotoxic effect may occur due to the fact that lettuce displays an increased sensitivity towards contaminants, such as petroleum, if compared with millet (Panicum miliaceum), radish (Raphanus L.), red clover (Trifolium pratense L.), and wheat (Triticum aestivum) (Banks and Schultz 2005). The aim of the latter experiments was to assess the influence of rhamnolipids on phytotoxicity during a 7-day long diesel oil biodegradation, which was carried out by a bacterial consortium (Fig. 3).

The rhamnolipid-supplemented biodegradation of diesel oil contributed to a further decrease of the GI for all the studied plant species, when compared to the samples with no biodegradation process. The phytotoxicity measured in soil samples after a diesel oil 
Fig. 2 Influence of rhamnolipids and diesel oil on the germination index of four studied plant species (a alfalfa, b mustard, c sorghum, d cuckooflower) after 7-day germination. $\mathrm{GI}=100-66 \%$ for the white area, 66-33\% for the light grey area and $33-0 \%$ for the dark grey area a

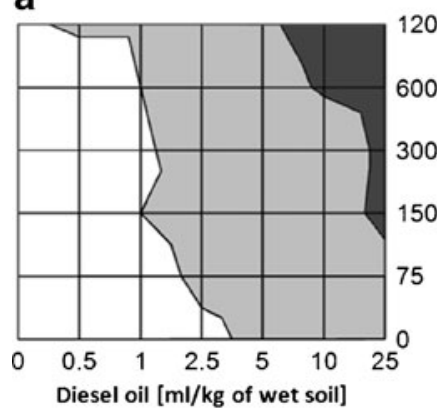

Diesel oil [ml/kg of wet soil]

C

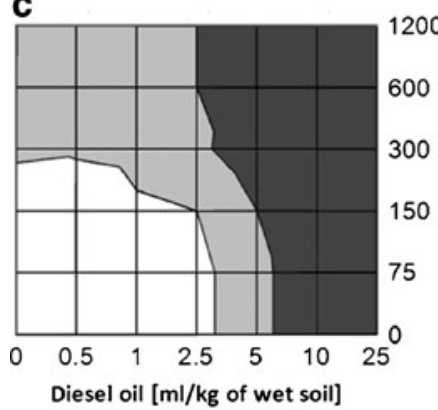

b

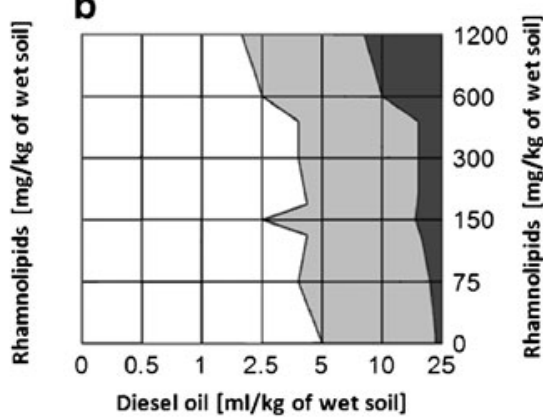

d

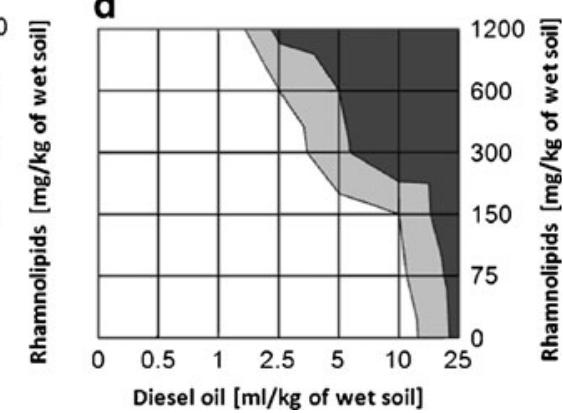

biodegradation process without rhamnolipid supplementation was lower compared to samples containing rhamnolipids at $150 \mathrm{mg} / \mathrm{kg}$ for the three studied plant species: alfalfa, mustard and sorghum. The differences were most notable at low concentrations of diesel oil for sorghum and mustard and at higher concen- trations for alfalfa. The cuckooflower did not exhibit any differences during the degradation of pure diesel oil and after the addition of the lower concentration of rhamnolipids. However, for each of the studied plant species, their germination index considerably dropped in the samples containing a
Fig. 3 Influence of 7-day long biodegradation of diesel oil and rhamnolipids on the germination index of four studied plant species (a alfalfa, b mustard, c sorghum, d cuckooflower); $0 \mathrm{mg} / \mathrm{kg}$ of rhamnolipids is indicated by circles,

$150 \mathrm{mg} / \mathrm{kg}$ of rhamnolipids by squares and $600 \mathrm{mg} / \mathrm{kg}$ of rhamnolipids by triangles
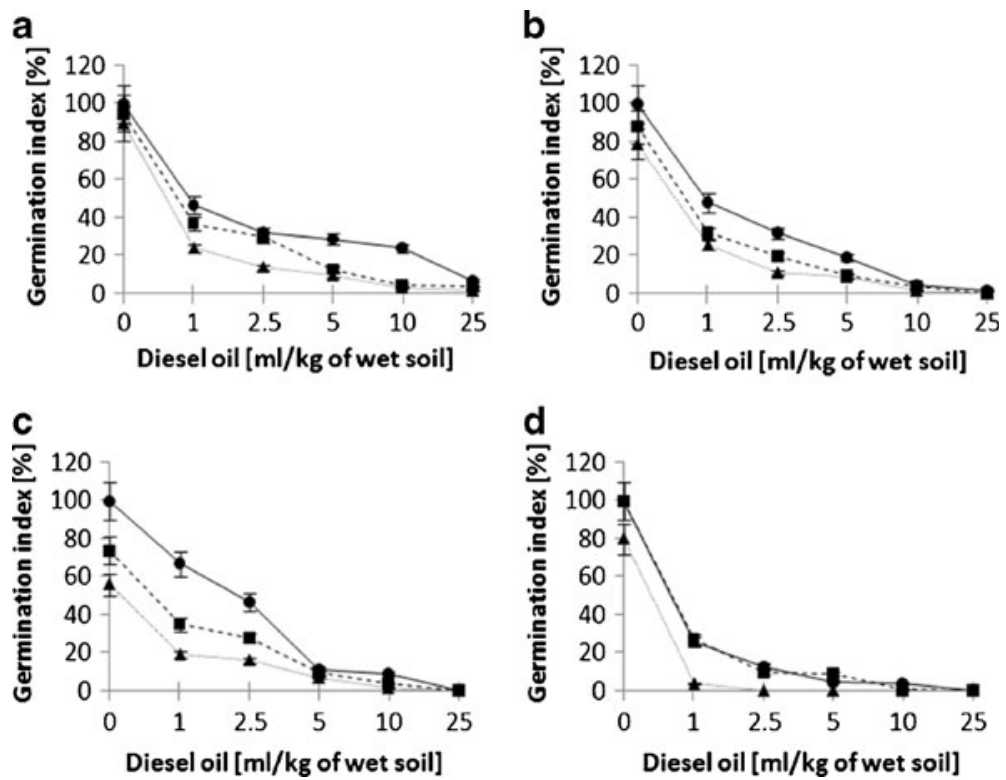
higher amount of the biosurfactant $(600 \mathrm{mg} / \mathrm{kg})$. This effect was most notable for the cuckooflower, and its GI dropped to insignificantly low levels even at the lowest concentration of diesel oil. Based on the obtained results, it can be concluded that the presence of rhamnolipids increases the toxicity of diesel oil in a petroleum-contaminated environment, which results in a significantly increased phytotoxicity.

\subsection{Inhibition of Plant Growth}

Both shoot and root biomass gradually decreased with the increasing concentration of diesel oil for all the studied plant species (Fig. 4). Similar to the results of the initial germination index experiments, the toxic effect was most apparent for sorghum. The use of higher rhamnolipid concentration $(600 \mathrm{mg} / \mathrm{kg})$ leads to a considerably higher drop of the dry matter values for both shoot and root compared to the samples containing a smaller concentration of the biosurfactant (150 mg/kg).

\subsection{TPH Removal and TTC Activity}

No significant differences were observed in terms of total petroleum hydrocarbon removal for samples without rhamnolipids and samples with $150 \mathrm{mg} / \mathrm{kg}$ of the biosurfactant (Fig. 5). The addition of rhamnolipids at $600 \mathrm{mg} / \mathrm{kg}$ resulted in a significant drop of the TPH removal efficiency for samples with a lower diesel oil content. This may have been caused by rhamnolipids being the more preferable carbon source. However, the results obtained during the TTC activity tests seem to contradict with this thesis.

The highest microbial activity was observed in the absence of rhamnolipids and at $150 \mathrm{mg} / \mathrm{kg}$ of the
Fig. 4 Changes in the shoot (above $x$-axis) and root (below $x$-axis) dry matter of four studied plant species (a alfalfa, b mustard, c sorghum, $\mathbf{d}$ cuckooflower) after 7 days of growth in soil with diesel oil and rhamnolipids present at different concentrations. Control is indicated by grey bars, $150 \mathrm{mg} / \mathrm{kg}$ of rhamnolipids by black bars and $600 \mathrm{mg} / \mathrm{kg}$ of rhamnolipids by white bars

\section{a}

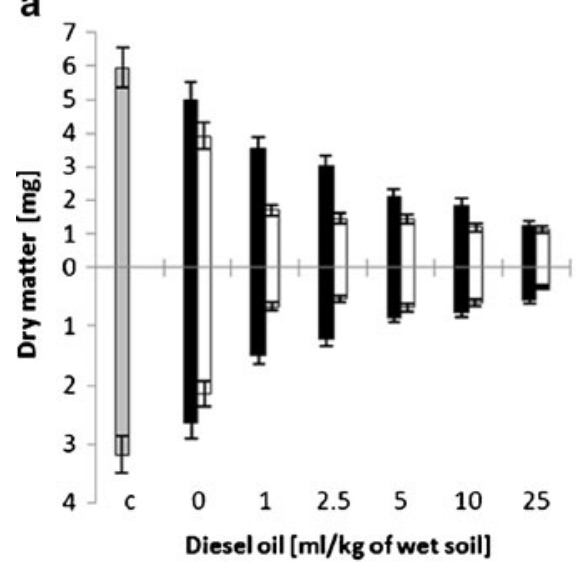

$$
\text { c }
$$

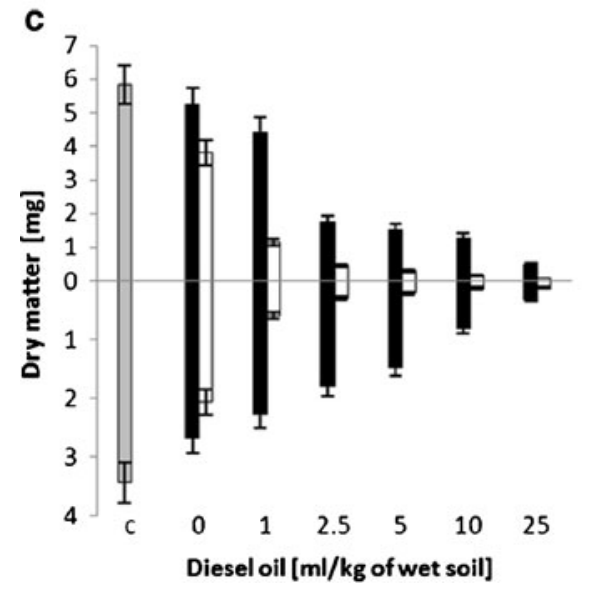

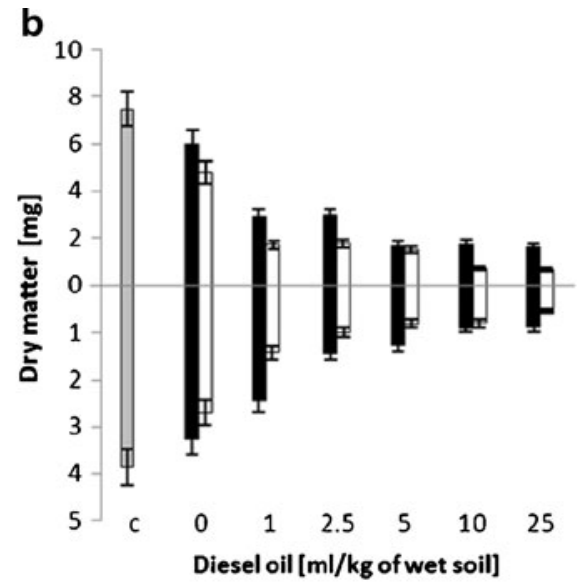

d

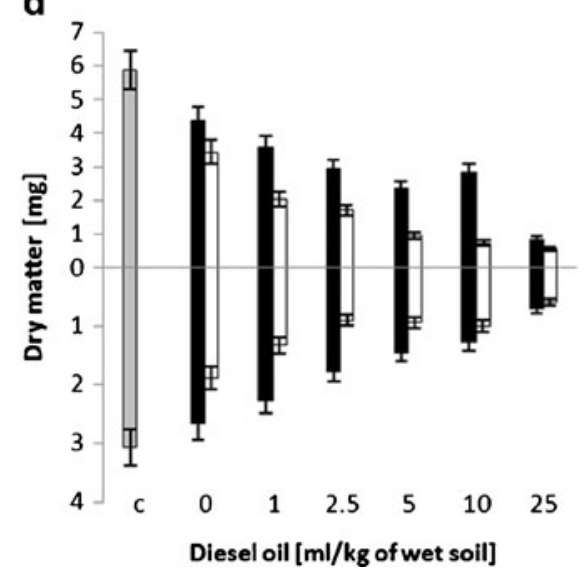




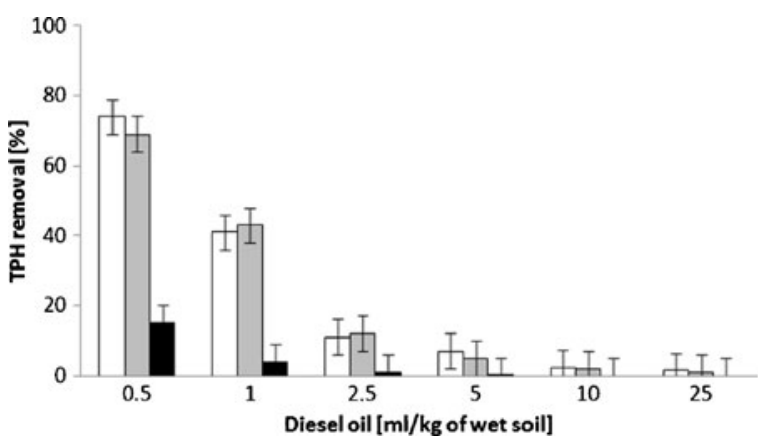

Fig. 5 Influence of rhamnolipids on the efficiency of total petroleum hydrocarbon removal after 7 days of biodegradation; $0 \mathrm{mg} / \mathrm{kg}$ of rhamnolipids (control) is indicated by white bars, $150 \mathrm{mg} / \mathrm{kg}$ of rhamnolipids by grey bars and $600 \mathrm{mg} / \mathrm{kg}$ of rhamnolipids by black bars

biosurfactant. As confirmed by our previous studies, the rhamnolipids do not interfere with the microbial growth at a concentration of 150 $\mathrm{mg} / \mathrm{l}$ (Owsianiak, Szulc et al. 2009); therefore, both curves were very similar (Fig. 6). Again, a notable decrease was observed for samples containing rhamnolipids at $600 \mathrm{mg} / \mathrm{kg}$. At 2.5 and $5 \mathrm{ml} / \mathrm{kg}$ of diesel oil, the microbial activity was much higher for samples without rhamnolipids and samples with the lower concentration of the biosurfactant, compared to the samples with a higher rhamnolipid content. The overall activity decreased with the increasing concentration of diesel oil. This may suggest that the rhamnolipids increase the toxicity of diesel oil towards the microbial consortium at a low contamination level. However, Shin et al. reported that even the sole presence of rhamnolipids

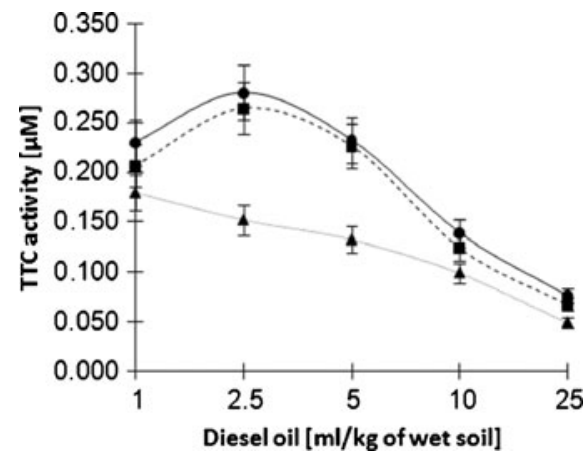

Fig. 6 Influence of rhamnolipids and diesel oil present in the soil sample on the measured TTC activity after 7 days of biodegradation; $0 \mathrm{mg} / \mathrm{kg}$ of rhamnolipids is indicated by circles, $150 \mathrm{mg} / \mathrm{kg}$ of rhamnolipids by squares and $600 \mathrm{mg} / \mathrm{kg}$ of rhamnolipids by triangles may be toxic to the microorganisms and result in an inhibited biodegradation of polycyclic aromatic hydrocarbons (Shin et al. 2005).

The progressive decrease of the germination index, plant growth and microbial activity may be caused by changes induced by rhamnolipids in the cell membrane permeability. The fact that the biosurfactant interacts well with diesel oil droplets should also be considered (Chrzanowski et al. 2009), as increasing the water solubility of the otherwise hydrophobic compound may contribute to the increased toxicity as well. It is plausible that both phenomena occur simultaneously, which would result in an overall negative synergy. This effect should be of high priority when considering the use of this biosurfactant for the removal of residual petroleum compounds by soil flushing and biodegradation.

\section{Conclusions}

Our studies confirm that the sole presence of rhamnolipids may potentially be toxic to the natural vegetation. The observed phytotoxicity seems to be species dependent. Furthermore, the addition of rhamnolipids contributes to a significant increase of phytotoxicity in a diesel oil-contaminated soil, and this effect is further enhanced during a rhamnolipidsupplemented diesel oil biodegradation process. Most likely, the biosurfactant interacts with diesel oil particles and enhanced its toxicity towards plants. The obtained results show that the application of rhamnolipids in diesel oil cleanup methods carried out in situ may be limited due to increased phytotoxicity. Future studies will focus on finding an optimal concentration of rhamnolipids, which would be satisfactory in terms of biodegradation effectiveness, removal of residual hydrocarbons and phytotoxicity.

Acknowledgments This study was partially supported by the ICT 32-194/11 DS-MK. J. Wojtera is supported by the Foundation for Polish Science, from the European Union funding in frame of the Operational Programme 'Innovative Economy', Homing Plus programme. $€$ Chrzanowski is an official collaborator in this project. 
Open Access This article is distributed under the terms of the Creative Commons Attribution License which permits any use, distribution, and reproduction in any medium, provided the original author(s) and the source are credited.

\section{References}

Banks, M. K., \& Schultz, K. E. (2005). Comparison of plants for germination toxicity tests in petroleum-contaminated soils. Water, Air, and Soil Pollution, 167, 211-219.

Chrzanowski, Ł., Wick, L. Y., Meulenkamp, R., Kaestner, M., \& Heipieper, H. J. (2009). Rhamnolipid biosurfactants decrease the toxicity of chlorinated phenols to Pseudomonas putida DOT-T1E. Letters in Applied Microbiology, 48, 756-762.

Gunawardana, B., Singhal, N., \& Johnson, A. (2010). Amendments and their combined application for enhanced copper, cadmium, lead uptake by Lolium perenne. Plant, Soil and Environment, 329, 283-294.

Guo, Y. P., Hu, Y. Y., Gub, R. R., \& Lin, H. (2009). Characterization and micellization of rhamnolipidic fractions and crude extracts produced by Pseudomonas aeruginosa mutant MIG-N146. Journal of Colloid and Interface Science, 331, 356-363.

Makkar, R. S., \& Rockne, K. J. (2003). Comparison of synthetic surfactants and biosurfactants in enhancing biodegradation of polycyclic aromatic hydrocarbons. Environmental Toxicology and Chemistry, 22, 2280-2292.

Margesin, R., Zimmerbauer, A., \& Schinner, F. (2000). Monitoring of bioremediation by soil biological activities. Chemosphere, 40, 339-346.

Millioli, V. S., Servulo, E. L. C., Sobral, L. G. S., \& De Carvalho, D. D. (2009). Bioremediation of crude oilbearing soil: evaluating the effect of rhamnolipid addition to soil toxicity and to crude oil biodegradation efficiency. Global NEST Journal, 11, 181-188.

Mosse, K. P. M., Patti, A. F., Christend, E. W., \& Cavagnaro, T. R. (2010). Winery wastewater inhibits seed germination and vegetative growth of common crop species. Journal of Hazardous Materials, 180, 63-70.
Mulligan, C. N. (2009). Recent advances in the environmental applications of biosurfactants. Current Opinion in Colloid and Interface Science, 14, 372-378.

OECD (Organisation for Economic Cooperation and Development) (1984). Earthworm, acute toxicity tests. Guideline no. 207. OECD, Paris.

Owsianiak, M., Chrzanowski, Ł., Szulc, A., Staniewski, J., Olszanowski, A., Olejnik-Schmidt, A., \& Heipieper, H. J. (2009). Biodegradation of diesel/biodiesel blends by a consortium of hydrocarbon degraders: effect of the type of blend and the addition of biosurfactants. Bioresource Technology, 100, 1497-1500.

Owsianiak, M., Szulc, A., Chrzanowski, Ł., Cyplik, P., Bogacki, M., Olejnik-Schmidt, A. K., \& Heipieper, H. J. (2009). Biodegradation and surfactant-mediated biodegradation of diesel fuel by 218 microbial consortia are not correlated to cell surface hydrophobicity. Applied Microbiology and Biotechnology, 84, 545-553.

Pornsunthorntawee, O., Chavadej, S., \& Rujiravanit, R. (2009). Solution properties and vesicle formation of rhamnolipid biosurfactants produced by Pseudomonas aeruginosa SP4. Colloids and Surfaces. B, Biointerfaces, 72, 6-15.

Santa Anna, L. M., Soriano, A. U., Gomes, A. C., Menezes, E. P., Gutarra, M. L. E., Freire, D. M. G., \& Pereira, N., Jr. (2007). Technical note: use of biosurfactant in the removal of oil from contaminated sandy soil. Journal of Chemical Technology and Biotechnology, 82, 687-691.

Shin, K. H., Ahn, Y., \& Kim, K. W. (2005). Toxic effect of biosurfactant addition on the biodegradation of phenanthrene. Environmental Toxicology and Chemistry, 24, 2768-2774.

Silva, S. N. R. L., Farias, C. B. B., Rufino, R. D., Luna, J. M., \& Sarubbo, L. A. (2010). Glycerol as substrate for the production of biosurfactant by Pseudomonas aeruginosa UCP0992. Colloids and Surfaces. B, Biointerfaces, 79, 174-183.

Urum, K., Pekdemir, T., \& Copur, M. (2004). Surfactants treatment of crude oil contaminated soils. Journal of Colloid and Interface Science, 276, 456-464.

Wen, J., McLaughlin, M. J., Stacey, S. P., \& Kirby, J. K. (2010). Is rhamnolipid biosurfactant useful in cadmium phytoextraction? Journal of Soils and Sediments, 10, 1289-1299. 